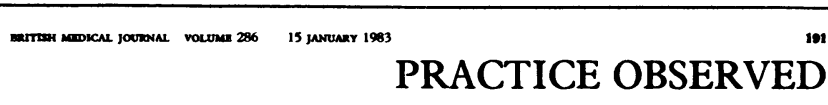

\section{General Practice in 2000}

\section{Alma Ata Declaration}

JOHN HORDER

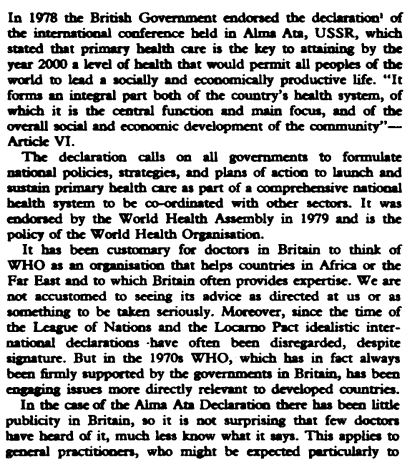

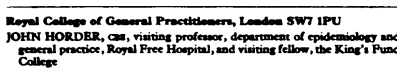

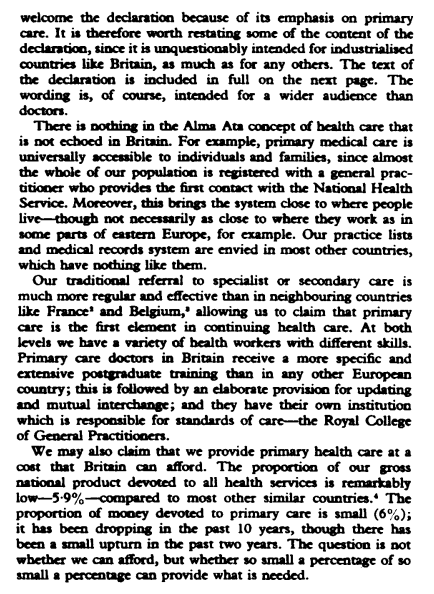

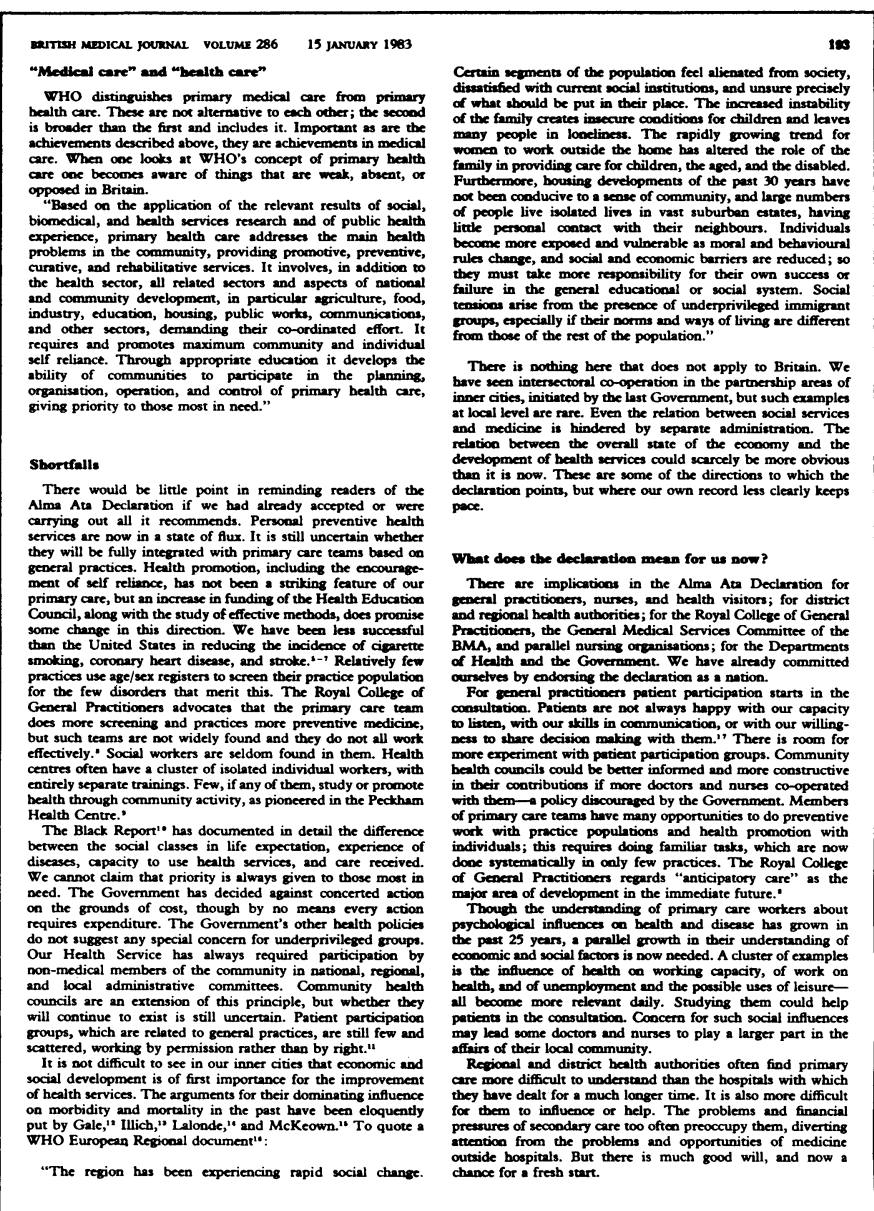

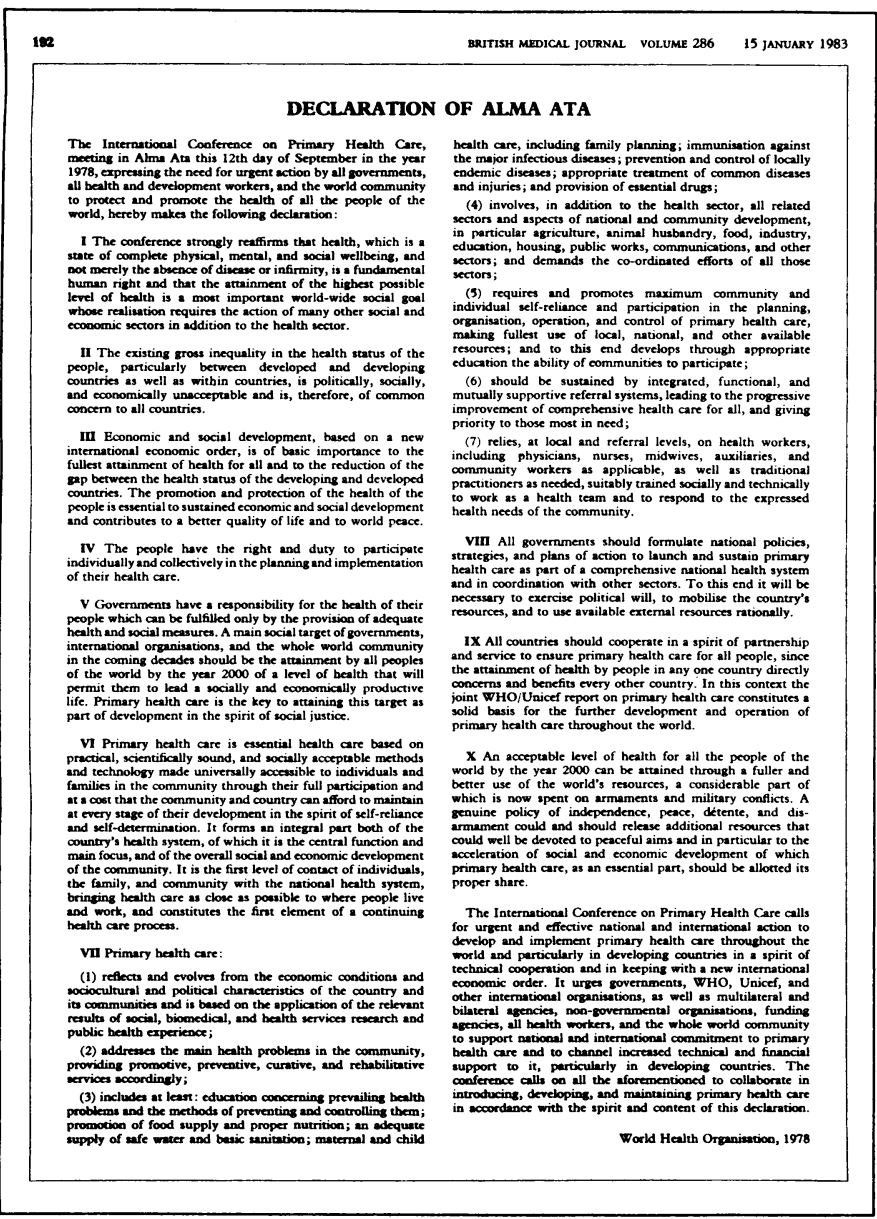

194

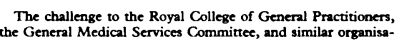

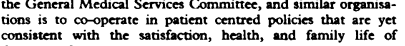

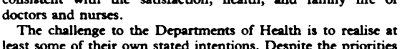

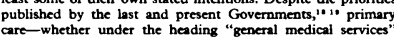

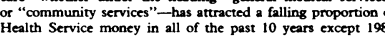

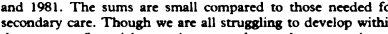

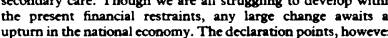

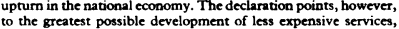

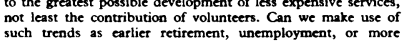

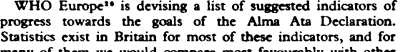
in the categries requested by $\mathrm{wH}$ as parr of our national
obigsation.

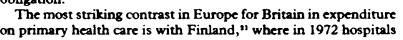

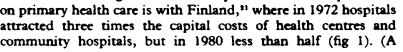

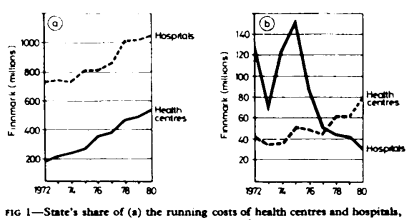

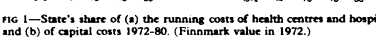

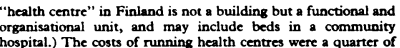

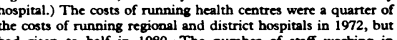

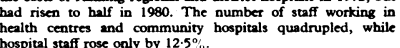

Conclustion

The diagram" in fig 2 illustrates two possible relations
between primary bealth are and the rest of mediciche. In thinting

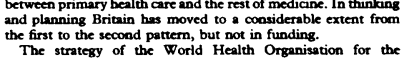
leisure?

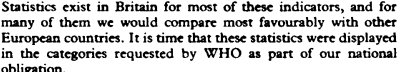

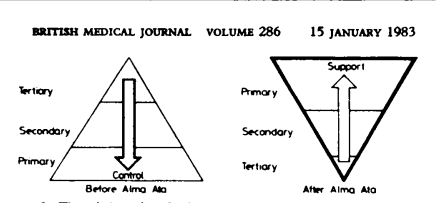

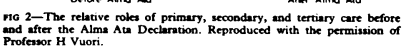

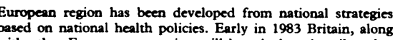
progress has been made towards the ideals of the Alma Ata

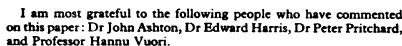

\section{Neferences}

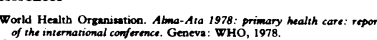

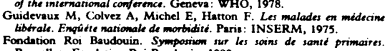

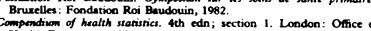

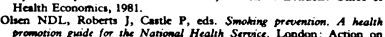

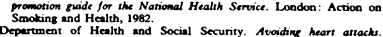

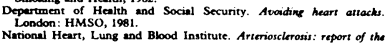

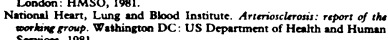

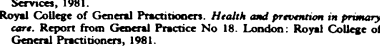

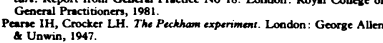

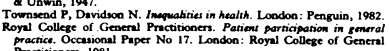

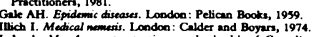

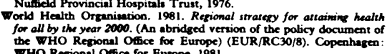

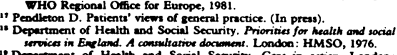

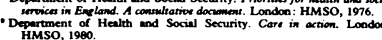

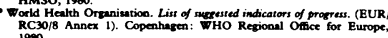

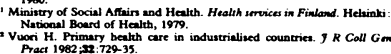

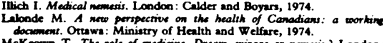

$\underline{\underline{m}}$

亦 